\title{
Surface feeding behavior of humpback whales in the Magellan Strait
}

\author{
Comportamientos de alimentación superficial de las ballenas jorobadas
} en el estrecho de Magallanes

\author{
Jorge Acevedo ${ }^{1,2}$, Jorge Plana ${ }^{3}$, Anelio Aguayo-Lobo ${ }^{4}$ and Luis A. Pastene ${ }^{5}$ \\ ${ }^{1}$ Centro Regional de Estudios del Cuaternario de Fuego Patagonia y Antártica (Fundación CEQUA), 21 de Mayo 1690, \\ Casilla 737, Punta Arenas, Chile. jorge.acevedo@cequa.cl \\ ${ }^{2}$ Universidad de Magallanes, Av. Bulnes 01855, Punta Arenas, Chile \\ ${ }^{3}$ Independent Researcher, Ramón Menéndez Pidal 0294, Punta Arenas, Chile \\ ${ }^{4}$ Instituto Antártico Chileno, Plaza Muñoz Gamero 1055, Punta Arenas, Chile \\ ${ }^{5}$ Institute of Cetacean Research, Toyomi-cho 4-5, Chuo-ku, Tokyo 104-0055, Japan
}

\begin{abstract}
Surface feeding behavior of 37 identified humpback whales in the Magellan Strait are reported with the aim of describing feeding behavior and investigating whether differences in prey type determine the feeding strategy in this area. A total of three lunging and one bubbling behaviors are reported, of which two ('single straight-line bubble curtain' and 'sub-surface skimming') are novel behaviors for this species and each feeding behavior tended to be consistent in regards to the prey species available at a given time. However, our data set did not contain a sufficient sample size to fully interpret this association with the available prey species.
\end{abstract}

Key words: Lunging behavior, bubbling behavior, Eastern South Pacific, Megaptera novaeangliae

\section{INTRODUCTION}

Behavioral plasticity is common among vertebrates, and is particularly frequent among mammals (Eisenberg 1981, Partridge \& Green 1985). Since foraging behavior consumes a large portion of an animal's time budget, it is not surprising to see variation within populations (Partridge \& Green 1985). Humpback whales Megaptera novaeangliae (Borowski, 1781), feed on a variety of relatively small prey species (see Ingebrigtsen 1929, Jurasz \& Jurasz 1979, Watkins \& Schevill 1979, Hain et al. 1982, 1995, Hays et al. 1985, Kenney et al. 1985, Friedleander et al. 2009, Hazen et al. 2009) by engulfing a large volume of water containing prey and separating food and water using sieve-like baleen plates (Slijper 1962, Mackintosh 1965). However, humpback whales have unique behavioral and morphological adaptations that distinguish them from other baleen whales, because humpback whales capture prey by engaging in complex feeding maneuvers that are often accompanied, in several instances, by the use of air bubbles (Wiley et al. 2011). Moreover, these bubble-feeding behaviors appear to vary in nature among both individuals and regions (Wiley et al. 2011).

Behaviorally, two main feeding behaviors have been documented from surface observations of humpback whales, all in both the North Atlantic and North Pacific populations: (1) 'bubbling' where the whales produce underwater exhalations followed by lunge, and (2) 'lunging' where the lunge is not preceded by underwater exhalations (Ingebrigsten 1929, Jurasz \& Jurasz 1979, Watkins \& Schevill 1979, Hain et al. 1982, D'Vincent et al. 1985, Weinrich et al. 1992, Sharpe 2001, Leighton et al. 2004). For bubbling behavior, humpback whales are known to produce a variety of configurations, such as complete bubble nets (Ingebrigsten 1929, Jurasz \& Jurasz 1979, Wiley et al. 2011), curtains and clouds (Hain et al. 1982). Other regional specific foraging techniques, which may also involve the use of bubbles to manipulate prey organisms, include flick feeding and lob-tailing, where bubbles are injected into the water column by a rapid movement of the flukes (Jurasz \& Jurasz 1979, Hain et al. 1982, Weinrich et al. 1992). For the lunging behavior, humpback whales feeding near the surface also exhibit a variety of types, such as lateral (or rolling) and vertical lunge (Jurasz \& Jurasz 1979, Hain et al. 1982, Sharpe 2001, Cunning et al. 2011). Other regional specific behaviors include inverted lunge feeding (Jurasz \& Jurasz 1979), circular swimming/thrashing and inside loop (Hain et al. 1982). Hays et al. (1985) also described an additional 
feeding behavior in which humpback whales form and utilize a surface slick. Additionally, some whales also feed on the bottom (bottom rolling and jaw scuffing) (Swingle et al. 1993, Hain et al. 1995, Friedlaeander et al. 2009, Cunning et al. 2011).

The information regarding the feeding behavior used by humpback whales in the Southern Hemisphere is limited. For humpback whales in the Western South Pacific, three opportunistic foraging behaviors ('vertical', 'lateral' and surface 'skimming' lunge) have been observed during their southward migration (Gill et al. 1998, Stockin \& Burgues 2005, Stamation et al. 2007). In these cases, the prey species were a type of small schooling baitfish or euphausiids, such as Nyctiphanes australis. For the Eastern South Pacific humpback whale population, two feeding areas have been recently recognized, the historical feeding area on the Antarctic Peninsula (Kellogg 1929, Townsend 1935, Mackintosh 1965), and a new feeding area in the central-south portion of the Fueguian Archipelago, in the Magellan Strait, Chile (Gibbons et al.
2003, Acevedo et al. 2004'1 2007, Acevedo 2005) (Fig. 1). In the Antarctic Peninsula region, 'complete bubble net', 'lateral' and surface 'skimming' lunge behaviors were also reported, utilized for the capture of Antarctic krill (Euphausia superba) (Acevedo et al. 2008). In the Magellan Strait feeding area, the vast majority of whales apparently feed in mid-water and the limited observations mentioned regarding feeding behavior have only referred to 'vertical' lunge and possible 'flick' feeding behaviors for feeding on Fueguian sprats (Sprattus fueguensis) and lobster-krill (Munida rugosa) (Gibbons et al. 2003).

The aim of the present study was to provide the first qualitative descriptions of the surface feeding behaviors used by humpback whales in Magellan Strait, based on opportunistic surface events seen between the 2003-2007 austral summer seasons. Some of the feeding behaviors reported here are novel for humpback whales. Additionally, we examine the preliminarily hypothesis of whether differences in prey type could determine the surface feeding behavior observed in this feeding area.

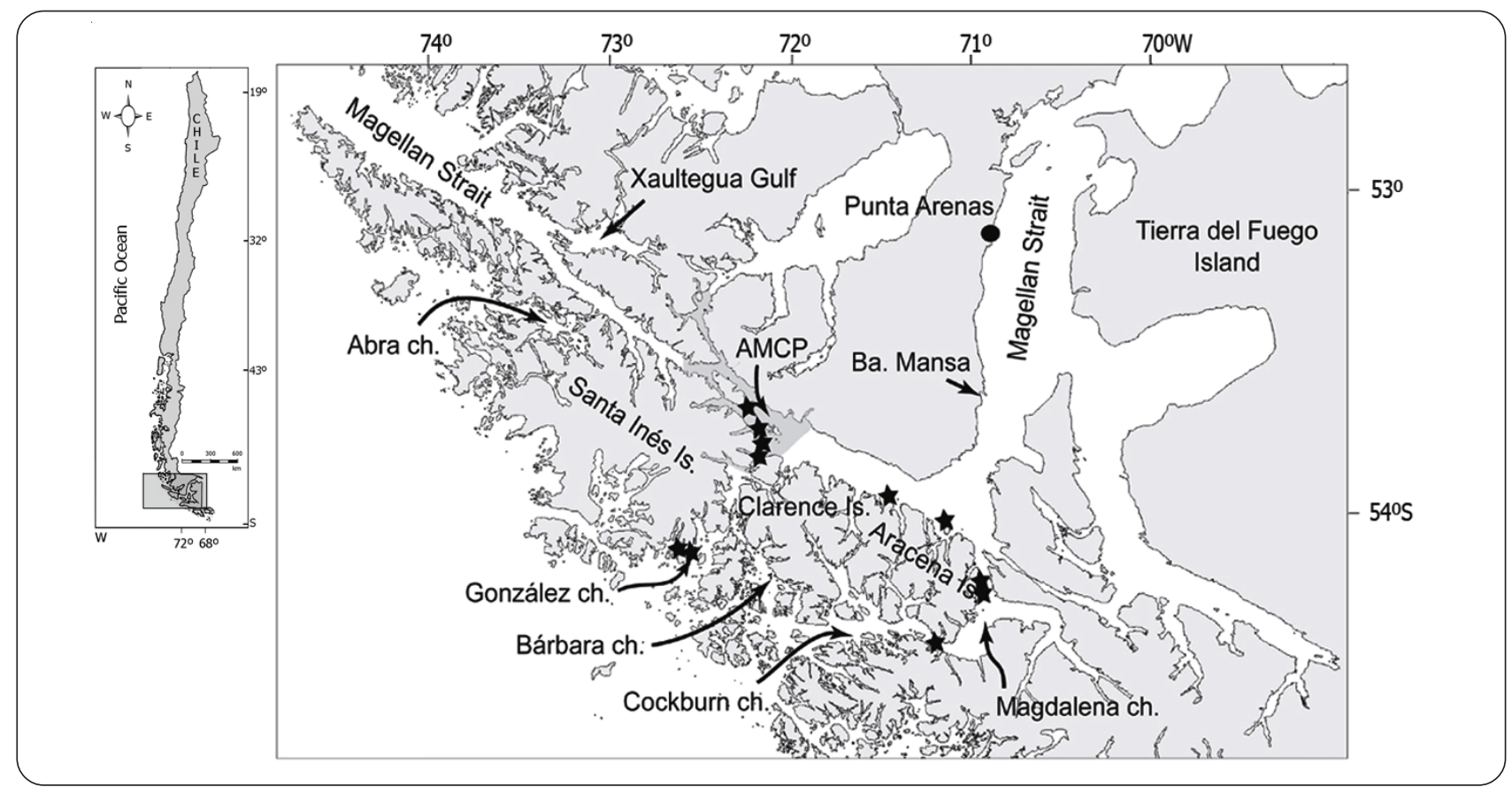

Figure 1. Feeding study area of Megaptera novaeangliae showing the localities where the surface feeding events were recorded (black stars) / Área de estudio de alimentación de Megaptera novaeangliae indicando las localidades donde fue registrada la actividad de alimentación superficial (estrellas negras)

\footnotetext{
${ }^{1}$ Acevedo J, P Acuña, C Olavarría, AAguayo-Lobo \& LA Pastene. 2004. Report of cetacean surveys in the Magellan Strait in the austral summer 2003/2004. Document SC/56/07 presented to the Scientific Committee of the International Whaling Commission. Sorrento, Italy, $10 \mathrm{pp}$. [Available from the Office of IWC].
} 


\section{Materials And Methods}

\section{STUdY AREA}

The surface observations were made in the Magellan Strait feeding area that encompasses the central-south portion of the Continental and Fueguian Archipelago from Mansa Bay to the north of Xaultegua Gulf, including the western area of Magellan Strait and the waters around Aracena and Clarence Islands, and channels of the SE coast of Santa Inés Island (Fig. 1). Part of the study area included the Marine and Coastal Protected Area 'Francisco Coloane'.

\section{Field OBSERVATIONS}

Opportunistic observations of surface feeding behavior were made during the research surveys (including photoidentification and skin biopsy experiments) conducted by the Fundación Centro de Estudios del Cuaternario (CEQUA Foundation). The feeding observations were made from the motor-vessel Chonos $(16 \mathrm{~m})$ between the 2003 and 2007 austral summer seasons. All observations of surface feeding were made at close distances (4-20 m) from the whales during daylight and under favorable weather conditions (wind speed less than 20 knot and visibility of 3-4 nm), and were complemented by digital photographs as well as video image recording. For consistency and clarity we used the feeding ecology terminology used in previous studies (e.g., Jurasz \& Jurasz 1979, Hain et al. 1982).

The prey species eaten by humpback whales at the surface were observed and photographed in the field and then collected using a WP2 net of $250 \mu \mathrm{m}$ mesh plankton net, and the fish (dying or dead on the surface) were collected using a hand net of $2 \mathrm{~cm}$ mesh net mounted on a pole. Prey species were identified at the laboratory to the lowest taxonomic level. In some cases the prey species being consumed by the whales were also filmed under the surface using a small underwater video system UWC325. All whales engaging in feeding activities were photoidentified (Katona et al. 1979) to investigate whether the same individuals used multiple feeding behaviors for the same or different prey species.

The feeding behaviors observed in the Magellan Strait humpback whales at the surface are presented using schematic figures. In addition we estimated the angle on the sagittal plane when the whale intercepted the surface. The angles were measured from a set of pictures using a digital protractor.

\section{Results AND Discussion}

A total of 20 opportunistic observations of surface feeding behavior involving 37 identified whales were made in the Magellan Strait feeding area. A summary of the feeding behaviors observed in the study area is shown in Table 1.

\section{Single Straight-Line bubble CURTaIN}

There were four independent observations involving groups composed of two whales. The whales swam in the same direction and parallel to the coast at a distance of less than $30 \mathrm{~m}$ to the shoreline. When the whales dive, numerous small bubbles were observed at the surface, forming a regular and single straight-line of bubbles approximately 20 to $25 \mathrm{~m}$ long, suggesting that only one individual was blowing to create the line bubble curtain.

Table 1. Feeding behavior of humpback whales observed in the Magellan Strait I Comportamiento de alimentación observado en las ballenas jorobadas del Estrecho de Magallanes

\begin{tabular}{lcccl}
\hline Feeding modes & $\begin{array}{c}\text { Number of } \\
\text { groups tracked }\end{array}$ & $\begin{array}{c}\text { Group size } \\
\text { (range) }\end{array}$ & $\begin{array}{c}\text { Total observation } \\
\text { (min) }\end{array}$ & \\
\hline $\begin{array}{c}\text { Bubbling } \\
\text { 1) Single-line }\end{array}$ & 4 & 2 & 256 & Fueguian sprat \\
$\begin{array}{c}\text { Lunging } \\
\text { 2) Vertical } \\
\text { a) slow } \\
\text { b) fast }\end{array}$ & 4 & $1-3$ & 108 & Fueguian sprat \\
$\begin{array}{c}\text { 3) Lateral } \\
\text { 4) Skimming lunge }\end{array}$ & 2 & 1 & 5 & Fueguian sprat \\
a) Sub-surface & 4 & $1-2$ & 104 & Euphausiid \\
\end{tabular}


After that the individuals appeared at the surface blowing once or twice and then dived in opposite directions between the line bubble curtain and the coast (Fig. 2). No gulping was recorded at the sea surface suggesting that the whales fed below the surface. Then the whales swam slowly on the sea surface for 3-4 min and repeated the activity 2-4 times, close to the original starting point.

In all cases the surface behavior was synchronized between the members. This feeding behavior was observed only in coastal areas with cliffs of over $30 \mathrm{~m}$ in height. In all cases, the target prey species, which was observed jumping out of the water, collected and examined at the laboratory, were fueguian sprat.

\section{Vertical Lunge}

There were six independent observations involving ten identified whales. In this feeding behavior the whales swam below the sea surface appearing at the surface with their open mouth and a distended throat region, trapping the prey at the sea surface. Before the whales settled back into the water they closed their mouth at the surface.

Two variations, 'slow' and 'fast' vertical lunges were identified according to the speed and angle that the whales surfaced (Fig. 2). In the 'slow' vertical lunge the rostrum intercept the surface slowly at oblique angles (mean $=40^{\circ}$, range $=28^{\circ}-52^{\circ}$ ), with less than one-third of the body clearing the surface. Sometimes the whales settled back into position and slightly rolled to the right. In all the tracked groups $t(n=4)$ this behavior were observed in waters with depth $<100 \mathrm{~m}$ and were typically

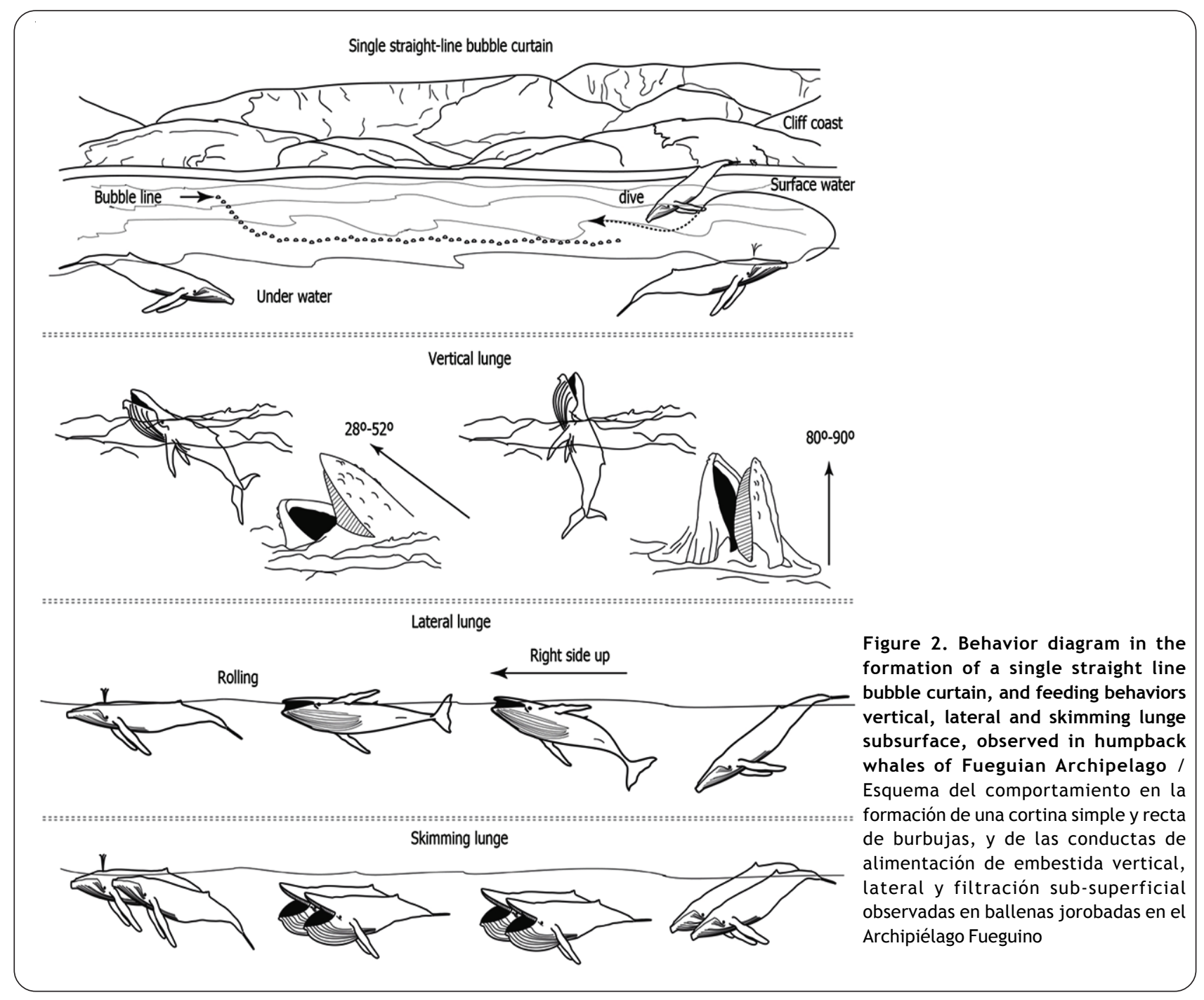


preceded by a blow, peduncle arch or fluke up. Such behaviors were always in the direction where flocks of sea birds and groups of Southern fur seals (Arctocephalus australis) were recorded simultaneously in active surface feeding. The group size ranged from one to three individuals and the target prey species was identified as the fueguian sprat. This activity was always synchronized among the members, in a close interindividual distance and repeated only two or three times for the different groups tracked. Only in one case a same individual (whale \#053) engaged in different feeding behaviors (slow vertical and skimming lunge) at different times and on different prey species.

In the 'fast' vertical lunge the whale surfaced with the rostrum at a perpendicular angle $\left(80^{\circ}-90^{\circ}\right)$ and more than one-third of the body cleared the surface before the whale settled back into the water in a vertical position. This variation was recorded only on two independent occasions, for a single individual in two different years, near the coast in waters with depths of more than $70 \mathrm{~m}$. In both cases the target prey species was identified (from photographs and collected samples) as the fueguian sprat. This fast vertical feeding was displayed only one or two times in each instance.

\section{LATERAL LUNGE}

There were four independent observations, involving seven identified whales, made in the middle of a channel and in coastal waters with the occurrence of kelp Macrocystis pyrifera. The whales repeatedly exhibited blow and fluke-up dives of short duration (1-2 $\mathrm{min}$ ) then intercepted the surface in a lateral position (right side up) with their open mouth at an angle of $11^{\circ}-54^{\circ}\left(\right.$ mean $\left.=41^{\circ}\right)$ for some seconds ( $\sim 10-15 \mathrm{~s})$ and a distended throat region (Fig. 2), suggesting that the feeding occurred just below and/or at the surface. During swimming at the surface, the whale moved forming a wide circular arc, and in most cases, the pectoral fin and part of the fluke was also observed above the surface. The end of the activity was marked by rolling the body upright at the surface followed by 2-5 blows. The same behavior was repeated several times in the same place. In all cases the prey species observed, filmed and collected was identified as E. lucens. In some cases flocks of sea birds were also recorded simultaneously in the same area feeding on the same prey species. Single animals or groups of up to two whales were involved. When more than one whale was involved in this behavior, lunges were synchronized between members.

\section{SKIMMING LUNGE}

There were six independent observations involving 12 identified whales. This feeding behavior, called here 'subsurface' skimming variation, was observed in the middle of a channel and in coastal waters during two consecutive days where two of those whales were re-sighted using this feeding behavior in different tracked groups t. The whales swam slowly in a normal position, and close enough to be observed clearly below the sea surface, breathing at intervals of 70-97 seconds in a straight direction or in a broad circle. Under the surface the whale's were seen with their open mouth but closed it briefly from time to time (average $=3$ times in each skimming event; range: 2-5) (Fig. 2). The behaviour was preceded by a dive without the fluke-up, and the end of the activity was marked by several blows $(n=4-5)$ at the sea surface. This behavior was repeated by the different tracked groups over a period of one hour and always in the same place. Single animals or groups of up to three animals were involved in this skimming variation, and when more than one animal was involved, the lunges were often synchronized among members and in close interindividual distance. In all cases only aggregations of lobster-krill were observed and collected in the water column suggesting that the whales fed on this prey species. Only in one case did the same individual (whale \#053) engage in different feeding behaviors (skimming lunge and slow vertical lunge) at different times and on different prey species.

Humpback whales show an extremely varied use of foraging behavior and such behavioral plasticity is illustrated by the many types of strategies and configurations that have been observed in different localities. In the Magellan Strait, at least four feeding behaviors are reported for the humpback whales derived from surface observations. This number increases to five if variations of some of the feeding behaviors (two variations in vertical lunge feeding behavior) are included. Of these, two behaviors (single straight-line bubble curtain and sub-surface skimming lunge) are novel for this species, and the lateral lunge behaviors are also documented for the first time for the Magellan Strait humpback whales. The single straight-line bubble curtain and sub-surface skimming variation could be regional specific foraging techniques. Although the number of focal observations for each surface feeding behavior is limited, the lunging foraging techniques were more diverse than the bubbling behavior observed in this feeding area. 
The single bubbling feeding behavior reported here was always associated with the feeding on a single prey species (fueguian sprat) and was always used in locations showing particular geographic characteristics (cliff). There is considerable speculation when explaining whether the bubbles assist the whales in capturing their prey. Some authors suggest that bubbles could be used to contain prey spatially and serve as a barrier against which to herd them (Ingebrigtsen 1929, Jurasz \& Jurasz 1979), or that bubbles may aid in the detection of prey or serve to mask the approaching whale (Hain et al. 1982). Sharpe (2001) suggested that Alaskan humpback whales that fed mainly on Pacific herring use bubbles to manipulate prey behavior by constraining the movement of prey schools into more exploitable spatial arrangements or force the school upward in the water column, thus trapping them against the surface. Recent descriptions of the underwater behaviors employed by humpback whales to create bubble nets, suggest that some animals use the spiral net function to compact (concentrate) the whales' prey prior to capture, but other individuals use nets to contain prey (Wiley et al. 2011).

Meanwhile, the use of particular geographic characteristics as barriers has been observed only in dolphin's species to facilitate prey capture during feeding events (e.g., Würsig 1986). Although our data are limited, the combined use of air bubbles and the particular topography (cliff) in shallow waters close to the shoreline would be consistent with the function of constraining the movement of the school and compact the prey in the water column prior to capture. Clustering behavior is a common response of fish to predators or other frightening stimuli (Pitcher \& Parrish 1993).

The three lunging behaviors reported in the present study (vertical, lateral and skimming lunge) have been reported previously for humpback whales in others localities of the Southern Hemisphere (e.g., Gill et al. 1998, Stockin \& Burgues 2005, Stamation et al. 2007, Acevedo et al. 2008). However, the skimming lunge behavior reported for some individuals in the Southern Hemisphere were observed to skim slowly at the surface, thus the 'sub-surface skimming' observed in the Magellan feeding area can be considered a novel feeding variation that humpback whales use in this particular area to fed on lobster-krill in the water column. Moreover, surface feeding typically occurred in spatially restricted zones where the animal repeatedly crossed the same area. This same pattern describing humpback whales crossing in a spatially restricted zone have also been previously reported by Ware et al. (2011) for humpback whales that feed near the surface, suggesting that the whales are able to exploit a single and small patch.

In all independent surface feeding observations performed in the Magellan Strait, the humpbacks tended to be consistent in their behaviors regarding the prey species available at a given time. Individuals that used lateral and skimming lunge behaviors tended to be consistent in feeding on euphausiid and lobster-krill, respectively; while vertical lunge and single straight-line bubble curtain behaviors were seen only when feeding on fueguian sprat. Moreover, the specific use of one or another behavior to feed on one or another prey species was demonstrated by humpback whale \#053 that used slow vertical lunge behavior to feed on fueguian sprat and sub-surface skimming behavior to feed on lobster krill, on a different occasion. However, our data set did not contain a sufficient sample size to fully interpret this association with the prey species available.

Until now, the factors that influence the choice of a determined feeding behavior are still unknown. Variations of the feeding behavior among individuals or between regions have been related to the characteristics of prey species, distribution in the water column, mobility behavior of the prey, variations in food supply and shape of the prey school (Jurasz \& Jurasz 1979, Watkins \& Schevill 1979, Weinrich et al. 1992, Friedleander et al. 2009, Hazen et al. 2009). The choice of feeding behavior may also be based upon the usefulness in a particular habitat (sea floor), as occurs for minke whales in the San Juan Islands (Hoelzel et al. 1989), or as related to the cliffs in this study (single straight-line bubble curtain feeding behavior). Individual preferences can also play an important role in the choice of a feeding tactic (Nowacek 1999). The maternal transmission and/or cultural transmission have also been suggested as other factors that might influence the choice of a particular feeding behavior over another behavior (Johnston 1982, Rendell \& Whitehead 2001), given that dependent humpback whale calves have been observed practicing the same elementary forms of feeding used by their mother (Weinrich et al. 1992, Stamation et al. 2007). However, all these possible factors must be considered as a component more within the complex equation that dictates the feeding strategy of humpback whales.

The surface feeding behaviors reported here, in our view, represent an important step forward in the ecological understanding of a population of humpback whales that have not been studied as much as some of the other 
populations. However, our observations are confined to the surface and presume some things about the underwater behavior of the whales. For this reason, a more complete picture of the behavioral repertoire (surface and underwater behaviors) together with data on an estimate of prey field density should be obtained for exploring deeper questions of foraging ecology.

\section{ACKNowledgments}

We thank the Director of the Fundación CEQUA for providing support for our marine mammal studies. We also thank all the colleagues who participated in the different cruises. To Dr. Armando Mujica, Universidad Católica del Norte, for his help in identifying the euphausiid species collected. Finally, we are grateful to Dr. Ari Friedlaender and a second anonymous referee for greatly improving this manuscript. The humpback whale research was carried out between 2003-2007 under the Regional Center Program of CONICYT and GORE Magallanes.

\section{LITERATURE CITED}

Acevedo J. 2005. Distribución, fidelidad, residencia y identidad poblacional de la ballena jorobada, Megaptera novaeangliae, que se alimentan en las aguas del Estrecho de Magallanes, Chile. Tesis Maestría, Universidad de Magallanes, Punta Arenas, 144 pp.

Acevedo J, K Rasmussen, F Félix, C Castro, M Llano, E Secchi, M Saborío, A Aguayo-Lobo, B Haase, M Scheidat, L Dalla-Rosa, C Olavarría, P Forestell, P Acuña, G Kaufman \& LA Pastene. 2007. Migratory destinations of humpback whales from the Magellan Strait feeding ground, Southeast Pacific. Marine Mammal Science 23: $453-463$

Acevedo J, A Aguayo-Lobo \& J Plana. 2008. Conducta de alimentación de la ballena jorobada en la Península Antártica. Boletín Antártico Chileno 27: 21-22.

Cunning C, D Crain, TS Eaton, K Nuessly, A Friedlaender, T Hurst, S Parks, C Ware, D Wiley \& M Weinrich. 2011. Population-level lateralized feeding behaviour in the North Atlantic humpback whales, Megaptera novaeangliae. Animal Behaviour 82: 901-909.

D'Vincent CD, RM Nikon \& RH Hanna. 1985. Vocalizations and coordinated feeding of the humpback whale in Southeastern Alaska. Scientific Reports of the Whales Research Institute, Tokyo 36: 41-47.

Eisenberg J. 1981. The mammalian radiations. An analysis of trends in evolution, adaptation and behaviour, $630 \mathrm{pp}$. University of Chicago Press, Chicago.
Friedlaender AS, EL Hazen, DP Nowacek, PN Halpin, C Ware, MT Weinrich, T Hurst \& D Wiley. 2009. Diel changes in humpback whale Megaptera novaeangliae feeding behavior in response to sand lance Ammodytes spp. behavior and distribution. Marine Ecology Progress Series 395: 91-100.

Gibbons J, JC Capella \& C Valladares. 2003. Rediscovery of a humpback whale (Megaptera novaeangliae) feeding ground in the Straits of Magellan, Chile. Journal of Cetacean Research and Management 5: 203-208.

Gill PC, KJ Evan \& H Wapstra. 1998. Feeding by humpback whales in Tasmanian waters. Records of the Queen Victoria Museum Launceston 107: 1-5.

Hain JHW, GR Carter, SD Kraus, CA Mayo \& HE Winn. 1982. Feeding behavior of the humpback whale Megaptera novaeangliae in the western north Atlantic. Fisheries Bulletin 80: 259-268.

Hain JHW, SL Ellis, RD Kenney, PJ Clapham, BK Gray, MT Weinrich \& IG Babb. 1995. Apparent bottom feeding by humpback whales on Stellwagen Bank. Marine Mammal Science 11: 464-479.

Hays HE, HE Winn \& R Petricig. 1985. Anomalous feeding behavior of a humpback whale. Journal of Mammalogy 66: 819-821.

Hazen EL, AS Friedlaender, MA Thompson, CR Ware, MT Weinrich, PN Halpin \& DN Wiley. 2009. Fine-scale prey aggregations and foraging ecology of humpback whales Megaptera novaeangliae. Marine Ecology Progress Series 395: 75-89.

Hoelzel AR, EM Dorsey \& SJ Stern. 1989. The foraging specializations of individual minke whales. Animal Behaviour 39: 786-794.

Ingebrigtsen A. 1929. Whales caught in the North Atlantic and other seas. Rapports et Procès-Verbaux des Réunions / Conseil Permanent International pour l'Exploration de la Mer 56: 1-26.

Johnston TD. 1982. Selective costs and benefits in the evolution of learning. Advances in the Study of Behavior 12: 65-106.

Jurasz CM \& VP Jurasz. 1979. Feeding modes of the humpback whale (Megaptera novaeangliae) in Southeast Alaska. Scientific Reports of the Whales Research Institute, Tokyo 31: 69-83.

Katona SK, B Baxter, O Brazier, S Kraus, J Perkins \& H Whitehead. 1979. Identification of humpback whales by fluke photographs. In: Winn HE \& BL Olla (eds). Behavior of marine animals, pp. 33-34. Plenum Press, New York.

Kellogg R. 1929. What is known of the migration of some of the whalebone whales. Annual Report of the Smithsonian Institution 1928: 467-494. 
Kenney RD, MAM Hyman \& HE Winn. 1985. Calculation of standing stocks and energetic requirements of the cetaceans of the northeast United States outer continental shelf. U.S. Department of Commerce, NOAA Technical Memorandum NMFS-F/NEC-41: 1-99. [on line]<http://www.nefsc.noaa.gov/ publications/tm/pdfs/tmfnec41.pdf $>$

Leighton TG, SD Richards \& PR White. 2004. Trapped within a 'wall of sound' A possible mechanism for the bubble nets of humpback whales. Acoustics Bulletin 29: 24-29.

Mackintosh NA. 1965. The stocks of whales, 232 pp. Fishing News Books, London

Nowacek DP. 1999. Sound use, sequencial behavior and ecology of foraging bottlenose dolphins, Tursiops truncates. Doctoral dissertation, Massachusetts Institute of Technology/Woods Hole Oceanographic Institution, Cambridge / Massachusetts, 196 pp.

Partridge L \& P Green. 1985. Intraspecific feeding specializations and population dynamics. En: Silby RM \& RH Smith (eds). Behavioral ecology, pp. 207-226. Blackwell Scientific Publications, Oxford.

Pitcher TJ \& JK Parrish. 1993. Function of shoaling behaviour in teleosts. In: Pitcher TJ (ed). Behavior of teleost fishes, pp. 363-439. Chapman \& Hall, London.

Rendell L \& H Whitehead. 2001. Culture in whales and dolphins. Behavioral and Brain Science 24: 309-324.

Sharpe F. 2001. Social foraging of the southeast Alaskan humpback whale, Megaptera novaeangliae. Doctoral Thesis, Simon Fraser University, Burnaby, 141 pp.

Slijper EJ. 1962. Whales, 465 pp. Basic Book, London.

Stamation KA, DB Croft, PD Shaughnessy \& KA Waples. 2007. Observations of humpback whales (Megaptera novaeangliae) feeding during their southward migration along the coast of Southeastern New South Wales, Australia: Identification of a possible supplemental feeding ground. Aquatic Mammals 33: 165-174.
Stockin KA \& EA Burgess. 2005. Opportunistic feeding of an adult male humpback whale (Megaptera novaeangliae) migrating along the coast of southeastern Queensland, Australia. Aquatic Mammals 31: 120-123.

Swingle WM, SG Barco, TD Pitchford, WA McLellan \& D Ann Pabst. 1993. Appearance of juvenile humpback whales feeding in the near shore waters of Virginia. Marine Mammal Science 9: 309-315.

Townsend CH. 1935. The distribution of certain whales as shown by the logbook records if American whaleships. Zoologica, New York 19: 1-50.

Ware C, A Friedlaender \& DP Nowacek. 2011. Shallow and deep lunge feeding of humpback whales in fjords of the West Antarctic Peninsula. Marine Mammal Science 27: 587605.

Watkins WA \& WE Schevill. 1979. Aerial observation of feeding behavior in four baleen whales: Eubalaena glacialis, Balaenoptera borealis, Megaptera novaeangliae and Balaenoptera physalus. Journal of Mammalogy 60: 155163.

Weinrich MT, MR Schilling \& CR Belt. 1992. Evidence for acquisition of a novel feeding behavior: lobtail feeding humpback whales (Megaptera novaeangliae). Animal Behaviour 44: 1059-1072.

Wiley D, C Ware, A Bocconcelli, D Cholewiak, A Friedlaender, M Thompson \& M Weinrich. 2011. Underwater components of humpback whale bubble-net feeding behaviour. Behaviour 148: 575-602.

Würsig B. 1986. Delphinid foraging strategies. In: Schusterman RJ, JA Thomas \& FG Woods (eds). Dolphin cognition and behavior: A comparative approach, pp 347-359. Lawrence Erlbuam Associates, Hillsdale.

Received 23 June 2011 and accepted 20 October 2011 